\title{
The Impact of Innovative Technologies on the Formation of a New Strategy for the Development of the International Oil and Gas Business
}

Ivan A. Kapitonov, ${ }^{\ddagger *}$ Vladimir I. Voloshin, ${ }^{*}$ Tatiana G. Filosofova, ${ }^{\uparrow}$ and Dmitry N. Syrtsov ${ }^{i}$

\section{Abstract}

This article is dedicated to the urgent problem of forming a new strategy for the development of the international oil and gas business in the context of the global impact of innovative technology. The authors have identified a complex and multi-aspect nature of the interconnection between innovation and economic development. One should note that modern models of economic growth and development of the international oil and gas business which are aimed at the adequate reflection of reality should necessarily take into account the phenomenon of innovation and their diffusion as well as consider an innovation factor as both endogenous and exogenous variables. However, at present, separate sub-sectors of the Russian fuel and energy complex operate in the regime of both moral and physical deterioration of their production and resource potential. It was revealed that in order for the oil and gas business to act as a single entity and provide a synergetic effect in achieving energy and national economic security, it had the necessary organisational basis for its sustainable development, it is advisable to form a mechanism for coordinating the interests of the state and business in the development of the oil and gas complex. The coordinator of interests should be a state that can develop and implement a single integrated program for the development of the oil and gas industry and to influence on its segments to harmonise and stabilise development in the long term. The degree of the state participation, the instruments of its indirect impact on the functioning and development of the oil and gas business are, first of all, called upon to ensure the proper level of energy security of the state, taking into account both endogenous and exogenous factors in the development of the oil and gas complex.

Keywords: Venture Financing, Economy Globalisation, Innovative Technology, Fuel and Energy Complex, Energy Strategy

\footnotetext{
${ }^{\dagger}$ Department of Tariff Regulation in Energy Sphere, Plekhanov Russian University of Economics, 117997, 36 Stremiannyy Lane, Moscow, Russian Federation

$¥$ Department of Energy Policy, Institute of Economics of the Russian Academy of Sciences, 117218, 32 Nakhimovsky Ave., Moscow, Russian Federation

*Email: kapitonov_ivan@mail.ru

Î Institute of the Trade Policy, National Research University “Higher School of Economics” (HSE), 101000, 20 Myasnitskaya Str., Moscow, Russian Federation

i Department of Applied Economics, National University of Science and Technology "MISiS“, 119991, 4 Leninsky Ave., Moscow, Russian Federation

(C) 2019 Kapitonov et al. This is an Open Access article distributed under the terms of the Creative Commons Attribution License (http://creativecommons.org/licenses/by/2.0), which permits unrestricted use, distribution, and reproduction in any medium, provided the original work is properly cited.
} 


\section{Introduction}

In the Energy Strategy of Russia approved by the Government of the Russian Federation (until 2020, 2030 and 2035) was also determined the main role of the fuel and energy complex in the whole and the oil and gas industry, in particular, in the Russian economy. Since the production and sale of hydrocarbons is one of the most competitive sectors of the national economy, it is the driver of the implementation of a qualitative leap in the innovative development of other sectors of the economy, including hightech ones. For a long time, Russia's oil and gas complex as a "complex interindustry system for the extraction and production of fuel and energy, their transportation, distribution and use remains one of the most stable operating production complexes of the Russian economy" (Kozieva \& Kuzbozhev, 2007: 29).

The analysis of recent years' statistics confirms this circumstance and has shown that the significant influence of the fuel and energy complex (FEC) on the economy of the Russian Federation (Figure 1) remains. So, $50 \%$ of the country's tax revenues are provided by the FEC, while the share of the FEC is estimated at $30 \%$ of the country's gross domestic product (GDP). One of these patterns affecting international business is globalisation with its positive and negative sides, among which the most important place is occupied by the problems of the global influence of innovative technology. Another pattern that cannot be ignored is cyclicity (Rocha, 2016; De Boni, 2017). The cyclical nature of economic development and the associated economic crises are significant factors that affect the formation of development strategies (Atanelishvili \& Silagadze, 2018). Therefore, one of the most important areas is the strategy of innovative transformation of the national economy, a reorientation to the use of new innovative technology (Syrtsov \& Syrtsova, 2017). In many situations, the appearance or use of a unique new technology can radically change the market position or give the market an additional segmentation: a striking example of such a case in the FEC is the extraction of oil from bituminous sand and the industrial extraction of shale gas in the United States (Workshop materials "The Shale Gas Revolution: Risks and Opportunities for Russia", 2010). At the same time, the critical objective of oil and gas operators from hydrocarbon-rich countries is to master exclusive technology and knowledge through the technology transfer tool (TT) and achieve maximum possible independence from their imports (Kapitonov et al., 2017; Kapitonov \& Voloshin, 2017).

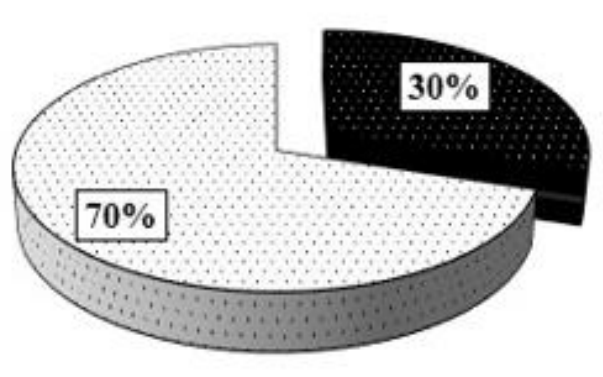

DFEC
DOthers

a)
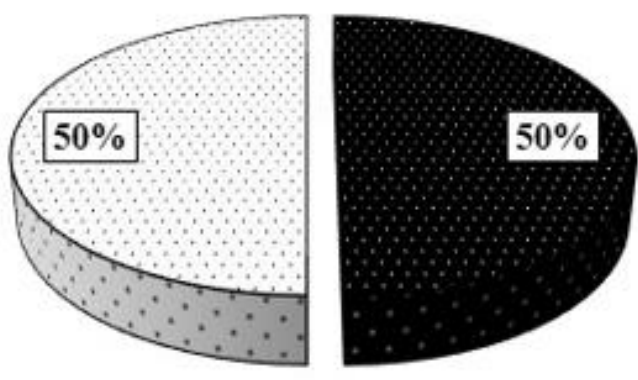

DEC DOthers

b)

Figure 1: Specific weight of indicators of the fuel and energy complex in the structure of the Russian economy: a) Share in GDP, \%; b) Share in tax receipts, \%; c) Share in exports, \%; d) Number of employees engaged in the industry, \%

Source: Filosofova, 2018 
These observations confirm the important role of the FEC modernisation in general and the oil and gas sector, in particular, in the overall strategy of innovative transformation of the national economy because this industry has an important impact on:

- energy security and security of the country;

- fully implemented resource and income support of other branches of the Russian Federation economy;

- balance and structure of the Russian Federation's foreign economic relations.

At the same time, in modern conditions, resource support for oil and gas business is considered to be inadequate and characterised by several problems which are caused by a number of factors the most important of which are:

- insufficient efficiency of the institutional mechanisms;

- obsolescence of technical and technological base;

- price and structural disproportions;

- problems in foreign economic activity caused by changes in the world market of energy markets.

Proceeding from the foregoing, the critical strategic guidelines for the country's long-term energy policy under the current conditions for the formation of a new strategy for the development of the international oil and gas business can be the following: energy security, energy efficiency of the economy, budget efficiency of energy and environmental safety of the FEC (Ushakov \& Kharchenko, 2018; Sakulyeva \& Kseniia, 2019; Akhmetshin et al., 2018a).

This research work is a part of the project entitled Peculiarities of applying the theory of international business by Russian oil and gas companies (Kapitonov, 2018) as we consider the theory of international oil and gas business. However, the previous research work (Kapitonov, 2018) includes a more general analysis of international companies. However, this research work presents a comparative analysis of international and domestic companies; parameters of classification of participants of international oil and gas business, and oil and gas megaprojects. Nonetheless, this research is a continuation of the previous one. However, the novelty of this research lies in studying innovative technology for the formation of a new strategy for the development of international oil and gas business. The main focus of this research is the application of innovative technology and its impact on the development of international oil and gas business.

Therefore, studying the impact of innovative technology on the formation of a new strategy for the development of international oil and gas business was based on a number of tasks:

- to consider the current state and prospects of development of the international oil and gas business to reveal new tendencies in the development of the world and national economy;

- to study the particularities of competition;

- to reveal the key factors that form the strategic vectors of the energy industry;

- to determine the conceptual, strategic directions for the development of the oil and gas business;

- to study the particularities of Energy Strategy of Russia until 2035;

- to analyse the mechanisms of stable development of market self-organisation in the oil and gas business.

In light of the background, this research begins with the discussion of methods applied in this research. Following this, we discuss the results and critically analyse in the sections that follow 'materials and methods section'.

\section{Materials and Methods}

At the present stage, the global energy market is characterised by a new model that reflects global trends and competition in the oil and gas business. The authors used methods of analysis, 
systematisation of data, review, modelling for a detailed study of the subject matter under research. Analysing various sources, it was found that in the modern economy, competition and competitiveness were the key concepts. Competition is a situation on the market in a certain period of time which have several hierarchical levels in which independent market players compete for limited best conditions for achieving their main strategic goals (Filosofova, 2013; Kokorev, 2019; Chernova et al., 2018). A number of factors can be identified, under the impact of which competitiveness is formed on the competitive market and characterised by a relatively long period of possible active use, and, therefore, allow a higher level of profitability: a positive reputation, qualified personnel, progressive management, one's own Research \& Development, new technology, etc. (Filosofova \& Karzunke, 2014).

It is established that a unique place in the modern development is occupied by unique knowledge and innovations that affect the development of international business and is inextricably linked with the national innovation model of development (Filosofova \& Bykov, 2008). As the key factors that form the strategic vectors for the development of the energy industry, the authors noted (Ageev \& Ovchinnikov, 2016; Ushakov et al., 2017):

- preservation of traditional fuels (oil and natural gas) as the prevailing energy sources in the world, even with the implementation of the most optimistic assumptions about the pace of development and introduction of alternative technology;

- urgent need to prevent catastrophic and irreversible climate damage on a global scale which ultimately requires a significant reduction in the carbohydrate capacity of the sources of energy used;

- recognising that the need to ensure reliable energy supplies and accelerate the transition to more environmentally friendly energy systems will require radical action by government authorities at both the national and local levels and their participation in joint international mechanisms.

The connection between the economic system and innovations is complex and multi-aspect. In addition, it is bilateral, that is, it is the innovations that affect the socio-economic system, and certain factors affect the formation of the parameters of the innovation resource. All this is expedient to consider in the context of dynamics.

The first models of economic growth took into account the impact of the classical factors of production: labour (L) and capital (K) (Cobb \& Douglas, 2010), the American scientists and the authors of the two-factor growth model, proved the directly proportional dependence of output (Y) on labour and capital:

$Y=F(K ; L)$

Further attempts to build a model of economic growth, as close as possible to reality, required the identification of all factors that affect the economic growth rate (Ushakov et al., 2017a: Ushakov et al., 2017b). At that, not all factors play the same role in economic growth. E. Denison carried out considerable computational and analytical work in this direction (Bartenev, 1996). Analysing the huge statistical material, the American scientist singled out 23 factors which affected the economic growth and noted a very significant impact of the factors of socalled "productivity" group which includes technology, location, scale and specialisation. So, to explain the dynamics of the economic system, it became necessary to take into account such a factor as technology $(T)$. At the same time, the model of economic growth acquires the following form:

$Y=F(K ; L ; T)$

The role of innovations in the process of economic development is treated differently in economic science. For example, several scientists note the endogenous impact of technological variables on economic growth in the example of the approach of Paul Romer and Arrow-Sheshinski (Golichenko, 2001). According to their calculations, the production function has the form: 


$$
Y=F\left(\omega_{1} L_{1} ; \omega_{2} L_{2} ; K\right)
$$

where $L_{1}$ and $L_{2}$ are qualified and unqualified work, respectively; $\omega_{1}$ and $\omega_{2}$ are coefficients of labour efficiency which depend on the number of qualitatively new technological developments that are embodied in the main $\mathrm{K}$ capital.

The study of R. Lucas (1988) seemingly allows us to interpret innovations as an exogenous factor in the theory of economic dynamics. In the field of his research is human capital, the effect of its impact on the process of economic development and the effectiveness of its use. The term "human capital" means the totality of the person's mental and physical abilities that can be used in the process of training and production activities. At the same time, there is an element of unexpectedness, unconsciousness and creative inspiration of a person in the labour process which allows counting the human capital, as well as innovations as an exogenous factor of economic growth (Loyaza, 1996).

The Wei-Bin Zhang Model (Zang, 1999) takes into account the impact of intellectuals on the dynamics of the economic process:

$Y=F\left(G ; L_{2} ; K\right)$

where $G$ is knowledge; $L_{2}$ is an indicator of physical labour.

Based on the above models, it should be noted that the current models of economic growth and development of the international oil and gas business are aimed at an adequate reflection of reality. One should necessarily take into account the phenomenon of innovations and their diffusion as well as consider an innovation factor as both endogenous and exogenous variables.

\section{Results}

The innovative model of the development, as an economic system, focuses on the creation of economic, organisational, legal and social conditions that ensure the efficient reproduction, development and use of the country's scientific and technical potential and introduction of domestic environmentally safe, new resource-saving technologies. The main incentive for introducing innovations for most business entities is the production of competitive products for making a profit. However, in a competitive environment, the desired result can be achieved by ensuring the efficiency of scientific, technical, economic, organisational, social and environmental factors.

At the level of the leading transnational oil and gas operators, innovation activity pursues the following aims: reduction of energy intensity, an increase of environmental friendliness, improvement of the quality of primary and secondary processing products, expanding the product line (Afanasieva, 2014: 45-47; Portella et al., 2017). At the same time, the most important advanced innovations in the oil and gas business that are under development in Russia and around the world include 3D and 4D geological and hydrodynamic modeling; hydraulic fracturing of the formation; coiled tubing technology; measurement during drilling; drilling small diameter wells, etc. (Natural Gas and Technology; Kayser, 2016; Neelova et al., 2018).

Formation of a globally competitive model of the international oil and gas business should be preceded by the development of a strategy for innovative development of the complex. The methodology of its creation should be based on a multilevel approach that takes into account the complexity of innovative development at the global, national and local levels. Thus, the organisational and economic mechanism of innovative development of the international oil and gas business consists of several strategic directions which are shown in Figure 2.

An analysis of the development of the world energy in different countries has revealed a wave and cyclical nature of their development with a period of about 50 years. The period of such a cycle is characterised by recovery phases, active and efficient development, a mutually conditioned sustainable economic system, the beginning of which is based on one or more basic innovations. As a result of discussions at the Davos Forum held in 2016, scientists came to the conclusion that "a change in the economic paradigm from the second industrial revolution which was based on the hierarchy of economic power and technology such as hydrocarbon energy, atomic and nuclear power, metallurgy 
and chemistry, to the third industrial revolution ( "green" economy), which is based on the principle of horizontal interaction between economic agents and the latest technology" (Davos Forum, 2016); generation of alternative energy, its conservation, accumulation, distribution on the basis of "energy" information technology, hybrid engines, additive production, artificial intelligence, nano- and biomaterials (Patriota et al., 2016; Samarina et al., 2018; Onyusheva et al., 2018; Akhmetshin et al., 2017).

The formation of a new strategy for the development of the international oil and gas business is in close connection with the main tasks of the energy strategy of Russia. An analysis of the evolution of programme documents in this field showed that initially the Energy Strategy of Russia for the period until 2020 was named as "determining the ways of achieving a qualitatively new state of the fuel and energy complex, increasing the competitiveness of its products and services in the world market, using the potential and setting priorities for the development of the complex, measures and mechanisms of the state energy policy taking into account the projected results of its implementation" (Energy Strategy until 2020, 2003: 1). The subsequent policy document (the Energy Strategy of Russia for the period until 2030) analysed and noted that "during the implementation of the Energy Strategy of Russia for the period until 2020, the adequacy of most of its most important provisions was confirmed to the real process of development of the country's energy sector, even in the conditions of harsh changes in external and internal factors that determine the main parameters of the functioning of the fuel and energy complex in Russia" (Energy Strategy until 2030, 2009: 2).

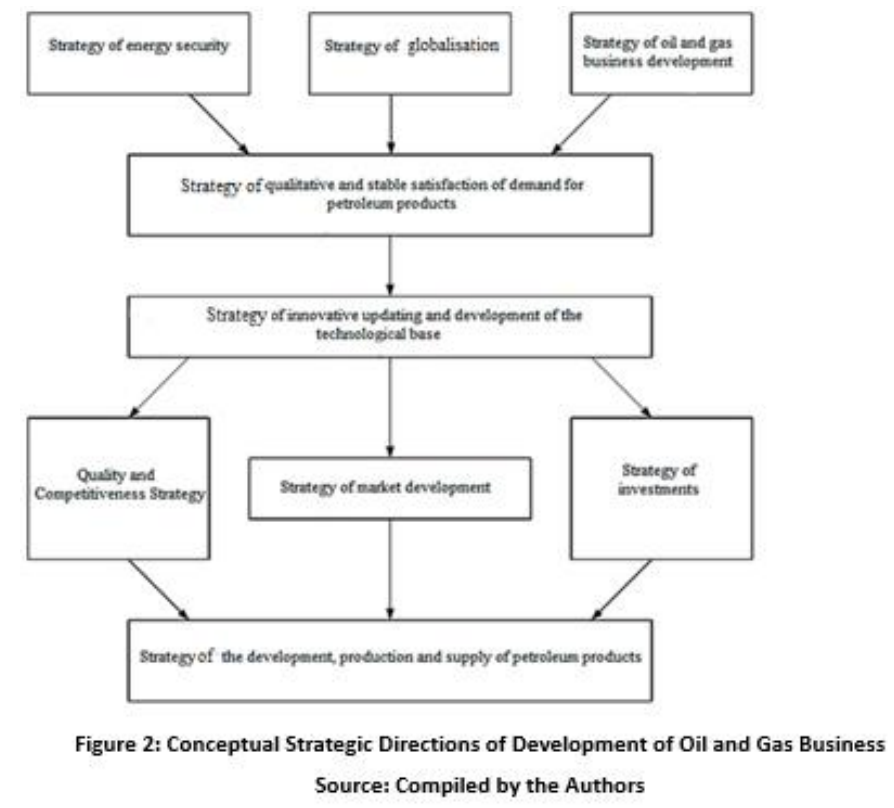

The most important strategic initiatives were new: formation of oil and gas complexes in the eastern regions of the country; development of the hydrocarbon potential of the continental shelf of the Arctic seas and northern territories of Russia; development and territorial diversification of the energy infrastructure and development of non-fuel energy; development of energy conservation (Energy Strategy until 2030, 2009).
Taking into account the system-forming role of the fuel and energy complex, the development and territorial diversification of the energy infrastructure was recognised a necessary condition for the sustainable social and economic development of the Russian Federation for the long term. The key strategic infrastructural projects in the FEC are: construction of the Eastern Siberia - the Pacific Ocean oil pipeline; construction of the oil product pipelines called North and South; 
construction of the North Stream and South Stream gas pipelines; construction of a multiline gas transmission system from the Yamal Peninsula as well as development of port and transport infrastructure for transportation of liquid hydrocarbons (oil, condensate, liquefied natural gas, wide fraction of light hydrocarbons) (Energy Strategy until 2030, 2009).

In its turn, the updated "Energy Strategy of Russia for the period until 2035 was developed in pursuance of the Decree of the President of the Russian Federation No. Pr-1471 dated 06 July
2013 on the adjustment of the Energy Strategy of Russia for the period until 2030 approved by the Russian Federation Government Resolution dated 13 November 2009 No. 1715-r.; extension of the strategic period to 2035 was carried out by the instructions of the Government of the Russian Federation (minutes of the meeting of the Government of the Russian Federation dated October 30 th 2013 No. 38)" (Energy Strategy until 2035). An important point was the approval of target indicators of the Russian Federation Energy System up to 2035 (Table 1).

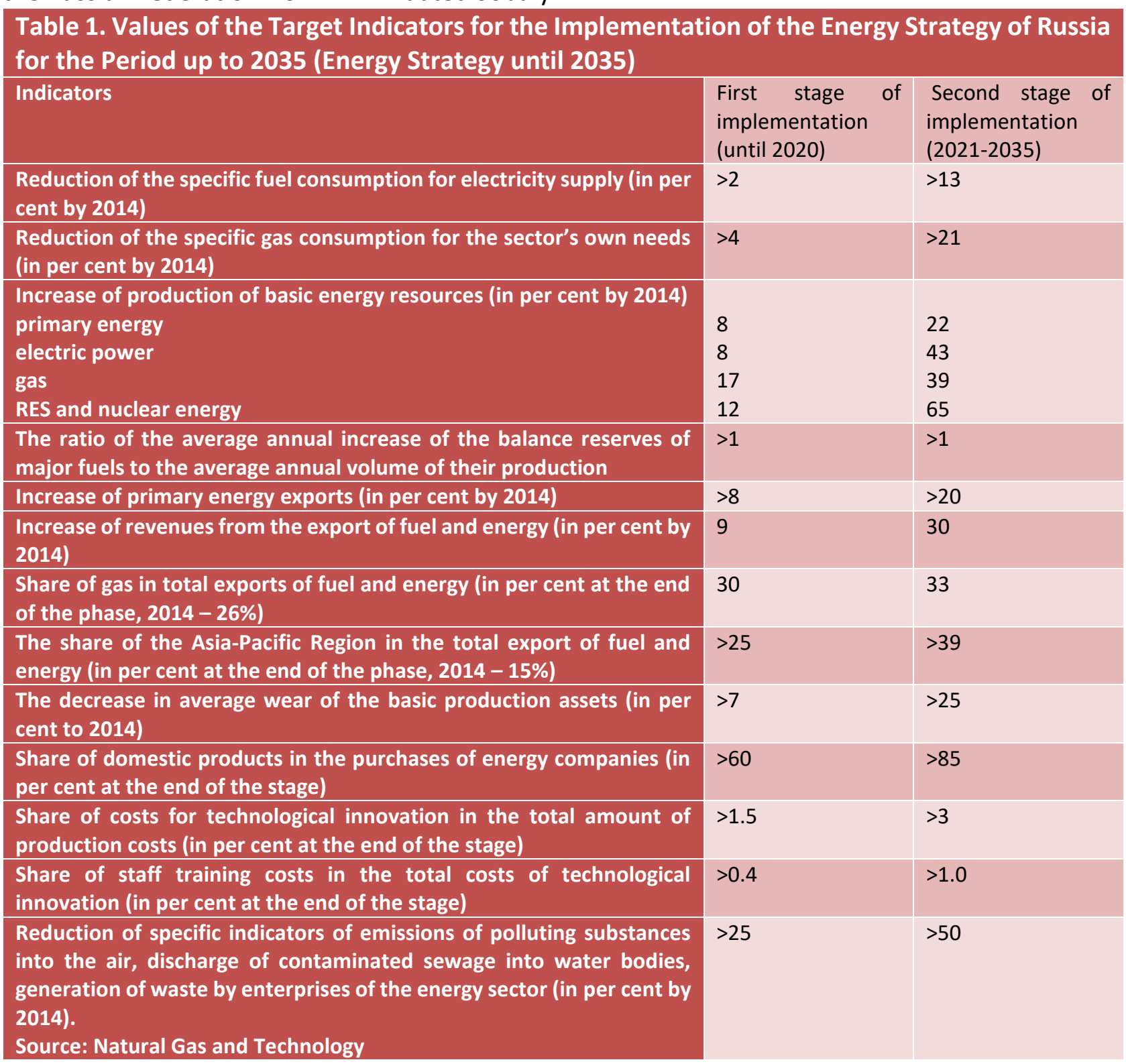

At the same time, the main barrier for the development of the oil and gas business should be noted: currently, individual sub-sectors of the Russian FEC operate in the mode of both moral and physical deterioration of their production and resource potential which has been formed. In this context, one has to certainly acknowledge the investments from the previous generations and to overcome the lack of investment resources to support efficient technology 
replenishment, the creation of mechanisms for state stimulation of innovations in the oil and gas business, and the creation and maintenance of a favorable investment climate are a top priority. The solution to this problem is impossible without developing a strategy for investing in the oil and gas complex both at the state level and at the level of regional complexes.

\section{Discussion}

According to the forecasts of the International Energy Agency, investments in the world oil and gas industry should amount to about 11 trillion dollars that is about $400-500$ billion dollars a year. About $85 \%$ of these investments will be directed to the search and extraction of natural resources (the IEA World Energy Outlook, 2012).

Aggressive competition forces global oil and gas companies to "accelerate the passage of innovations from the stage of conceptual comprehension and presentation of the idea to the stage of commercialization" (Pivovarov et al., 2011: 49). A wide range of possible organisational forms of financing innovative activity and using its results (organisation of its research units as cost centres, organisation of research units in the form of profit centres, strategic alliances, application of new financial models, and others. Filosofova (2018) creates conditions for the flexible operational management of the configuration of relations in this area (Silagadze, 2018). Thus, as the role of energy for the functioning and development of the entire economy of the state grew, the need for a balanced external economic energy policy for the protection of the state increased:

- from foreign business entities which take advantage of the internationalisation of the world economy sought to expand their activities to the territory of other states, focusing on their own profit rather than the economy of the host state;

- from the policy aimed at using the needs of national enterprises in energy resources in the interests of the energy owner or the owner of the energy supply infrastructure to the consumer.
These factors, as well as the need to optimise the budgetary policy of the state, led to the formation of the structure of the fuel and energy system. The structure of the system can be characterised as "horizontally" (when referring to the relations between the same type, singleorder components of the system) and the "vertical" (for example, the connection between the object and the class to which it belongs). It is the "vertical" structure that leads to the concept of levels of the system and the hierarchy of these levels.

In the context of sustainable development, the mechanisms of market self-organisation also function in the oil and gas business:

- The market encourages the world's oil and gas companies to increase their potential (first of all, financial one) on the way to maximising profits. The fundamental goal of the business is to achieve profit, which is directly the primary condition for creating the investment potential necessary for stable operations and development.

- The market mechanism positively influences the interest in increasing "the scale of the company and strengthening intracorporate ties due to concentration - the concentration of production in ever-larger enterprises" (Samarina et al., 2018: 144).

- Orientation to the consumer stimulates oil and gas "giants" to become more manoeuvrable, representing one more factor of stability of functioning and providing an opportunity for a more flexible reaction to changing customer requests.

- Market conditions require global oil and gas companies to increase their competitiveness, which depends significantly on the implementation of innovative potential (Mozgovaya, 2009).

Currently, state support for the development of oil and gas business can consist in providing investment benefits, reducing import duties on 
FEC equipment, accelerated depreciation of fixed assets, etc. (Figure 3).

From this position, the role of the state in ensuring the dynamic innovative development of the oil and gas business, according to the definition of M.N. Dudin, can be considered as "SMART-add-on, functions of which are reduced both to the definition of key development goals and tasks, to the overall investment support of priority innovative projects, and to compulsory participation in the creation of a modernised infrastructure complex and the formation of an institutional legal and business environment" (Veselovskiy \& Kirova, 2016: 35; Akhmetshin et al., 2018b).

State support for venture financing of innovative technology modernisation projects in Russia should be carried out in the following main areas (Figure 4).

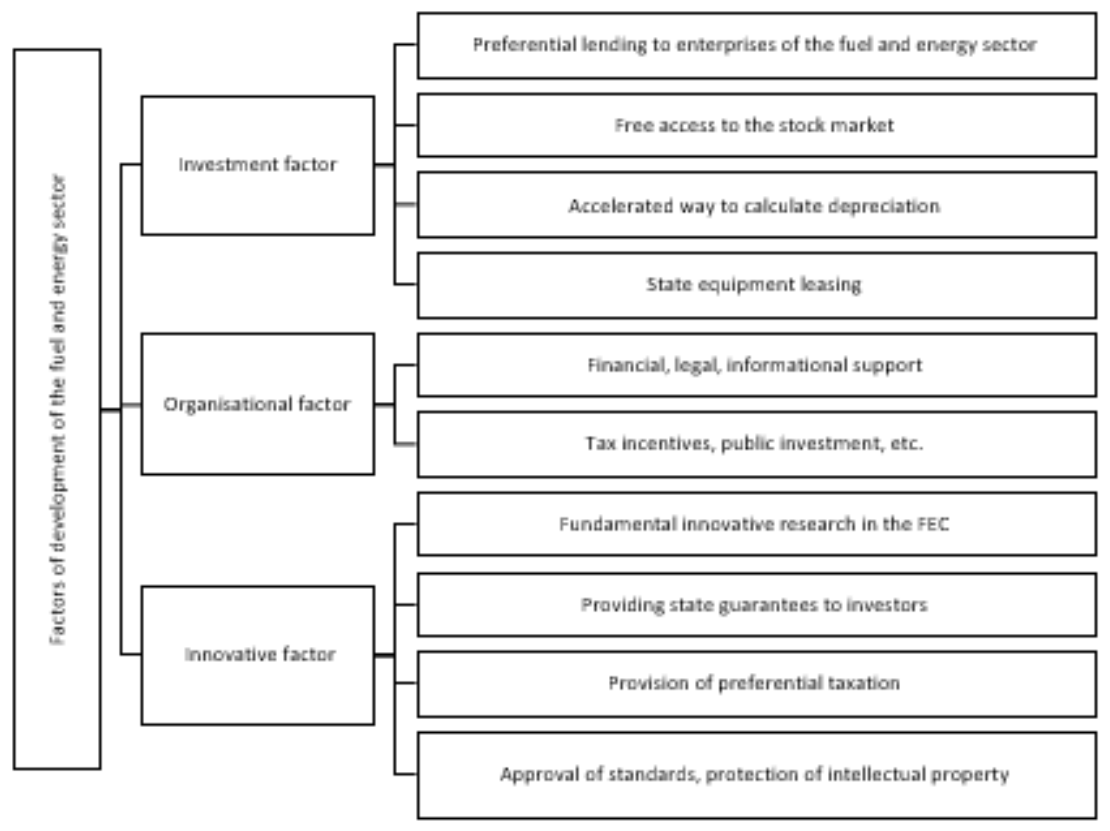

Figure 3: Factors of Oil and Gas Business Development and State Regulation Source: (Belyaeva, 2015: 15)

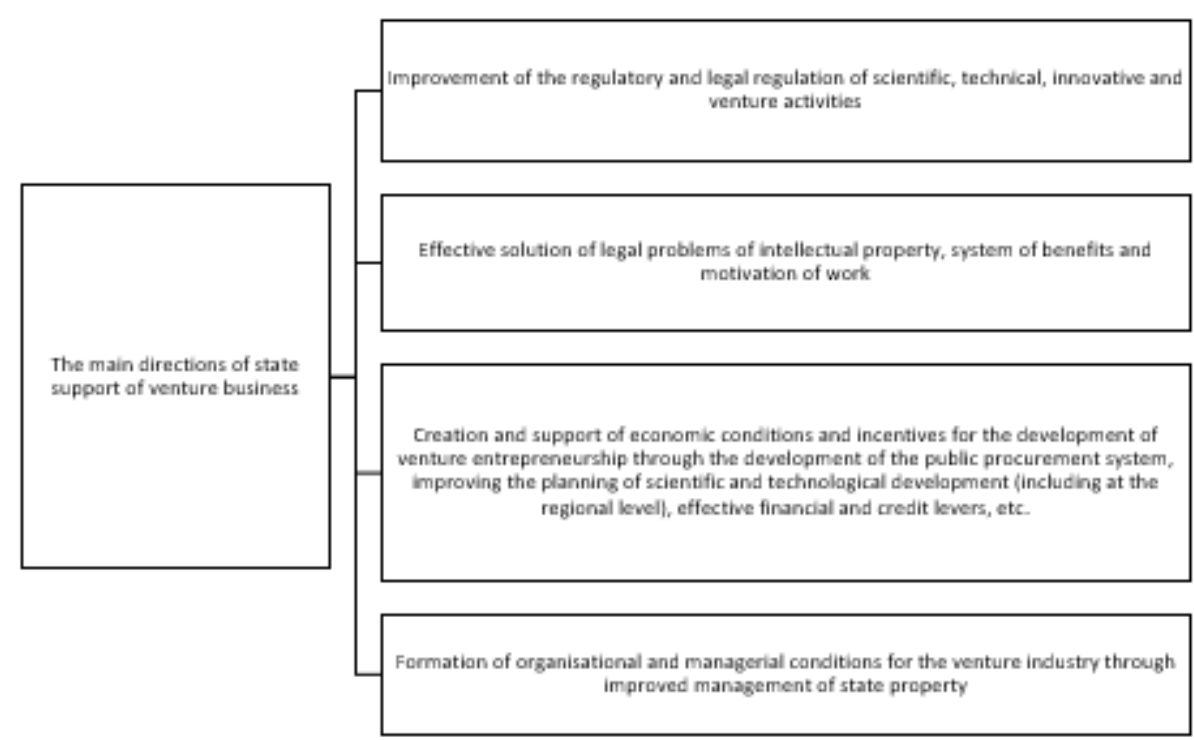




\section{Conclusion}

It is expedient to form a target federal fund for the modernisation and construction of new complexes and the allocation of funding for the reproduction of fixed assets and new construction on preferential terms. For the Russian companies that provide equipment for upgrading existing and newly constructed complexes, incentive tax privileges can be introduced, and subsidies for the acquisition or development of new equipment and technology can be provided to buyer companies. All this will increase the competitiveness of domestic oil and gas business.

The degree of state participation and the instruments of its indirect impact on the functioning and development of the oil and gas business are formed-to ensure a proper level of energy security of the state. The solution of this task consists in the formation of a long-term state energy policy that takes into account both endogenous and exogenous factors in the development of the oil and gas complex which goes beyond the standard technological problems of ensuring the reliability of energy supply systems.

The main problematic aspects of the management relations that currently arise between the state (at the level of its regions) and business in the oil and gas sector can be solved based on:

- formation of favourable financial and economic conditions for the establishment and development of small and medium-sized regional companies;

- coordination of efforts and ensuring interaction with the oil and gas business to solve the socio-economic problems of the producing territories;

- support of venture financing of innovative projects for modernisation of technology in the oil and gas sector.

In the light of the fact that there are prerequisites for the development of innovative processes of modernisation of the domestic oil and gas business with the use of venture funds to stimulate the introduction of innovative projects in the energy sector. , It is necessary to create favourable conditions for the development of high-risk investments in the Russian Federation, to develop a special system of motivation from the state for creation of venture funds and companies; to conduct constant monitoring of the state of affairs in the innovation sphere, to strengthen the protection that intellectual property rights and provide proper information support for venture investors.

\section{References}

Afanasieva, M. V. (2014). The basic directions of innovative development of fuel and energy complex abroad and in Russia. Energy Policy, 2, 43-54.

Ageev, A. I., \& Ovchinnikov, V. V. (2016). System designs of the global oil and oil products market. Economic Strategies, 4, 122-133.

Akhmetshin, E. M., Kopylov, S. I., Lobova, S. V., Panchenko, N. B., \& Kostyleva, G. (2018a). Specifics of the fuel and energy complex regulation: Seeking new opportunities for Russian and international aspects. International Journal of Energy Economics and Policy, 8(4), 169-177.

Akhmetshin, E. M., Vasilev,V. L., Bakhvalov, S. I., Prikhod'ko, A. N., \& Kazakov, A. V. (2017). Internal control in the system of innovation management in the modern business environment. International Journal of Economic Research, 14(15), 409-416.

Akhmetshin, E. M., Vasilev, V. L., Mironov, D. S., Zatsarinnaya, E. I., Romanova, M. V., \& Yumashev, A. V. (2018b). Internal control system in enterprise management: analysis and interaction matrices. European Research Studies Journal, 21(2), 728-740.

Atanelishvili, T., \& Silagadze, A. (2018). Formation of economic views in the ancient era. Bulletin of the Georgian National Academy of Sciences, 2(1): 191-196.

Bartenev, S. (1996). Economic theories and schools (History and modernity). Moscow: BEK Publishing House. 
Belyaeva, E. (2015, 08 December). Possible models of regulating renewable energy in Russia. Retrieved on 21 March 2019 from, http://thewallmagazine.ru/renewableenergy

Chernova, V.Y., Tretyakova, O.V., \& Vlasov, A.I. (2018). Brand marketing trends in russian social media. Media Watch, 9(3), 397-409

Cobb, Ch. W., \& Douglas, P. H. (2010). A Theory of Production. The American Economic Review, 18(1), 139-165

Davos Forum. (2016). Retrieved from http://expert.ru/2016/01/21/chetvertayapromyishlennaya-revolyutsiya

De Boni, L. A. B. (2017). Empirical theoretical proposal for the production of biodiesel. Periodico Tche Quimica, 14(28), 166-174

Dudin, M. N. (2015). Conceptual framework for the development of high-tech industry at the national level and in the scale of specific industrial regions. Regional Economy. Theory and Practice, 18 (393), 2-14.

Energy Strategy until 2020. (2003, 28 August) Retrieved on 18 March 2019 from, http://www.consultant.ru/document/cons_d oc_LAW_87926/

Energy Strategy until 2030. (2009, 13

November). Retrieved on 21 March 2019 from, http://www.consultant.ru/document/cons_d oc_LAW_94054/

Energy Strategy until 2035. Retrieved on 05 April 2019 from, http://www.energystrategy.ru/ab_ins/sourc e/ES-2035_09_2015.pdf

Filosofova, T. G. (2013). Competition and innovations. Leasing, 8, 25-33.

Filosofova, T. G. (2018). Management of export potential of industry and economic security of the state. Management in Russia and Abroad, 1, 37-41.

Filosofova, T. G., \& Bykov, V. A. (2008). Competition. Innovations. Competitiveness. Moscow: YUNITI-DANA.

Filosofova, T., \& Karzunke, I. (2014). Interim management a new tool to enhance a company's competitive performance under current global instability. International Relations 2014 Contemporary Issues of World Economics and Politics (pp. 155-159). Bratislava: Publishing House EKONÓM.

Golichenko, O. G. (2001). The problem of regulating economic growth in macroeconomic models. Economics and Mathematical Methods, 37 (4), 33-43.

IEA World Energy Outlook. (2012). Retrieved on 02 April 2019 from, www.worldenergyoutlook.org

Kapitonov, I. A. (2018). Peculiarities of applying the theory of international business by Russian oil and gas companies. Space and Culture, India, 6(4), 5-14, https://doi.org/10.20896/saci.v6i4.378

Kapitonov, I. A., \& Voloshin, V. I. (2017). Strategic directions for increasing the share of renewable energy sources in the structure of energy consumption. International Journal of Energy Economics and Policy, 7(4), 90-98.

Kapitonov, I. A., Korolev, V. G., Shadrin, A. A., \& Shulus, A. A. (2017). The role of small and medium-sized innovative enterprises in the solution of the import substitution task in oil and gas-sector segment of the Russian fuel and energy complex. International Journal of Energy Economics and Policy, 7(3), 137-145.

Kayser, M. (2016). Can we make the world a better place with solar 3D printing? Periodico Tche Quimica, 13(26), 9-13.

Kokorev, A.S. (2019). Digital economy: changes of values and guidance in business management. Moscow Economic Journal, 1, 28.

Kozieva, I., \& Kuzbozhev, E. H. (2007). Economic geography and regional studies (History, methods, state and prospects and location of productive forces). Moscow: Knorus.

Loyaza, N. V. (1996). The economics of informal sector: a simple model and some empirical evidence from Latin America. CarnegieRochester Conference Series of Public Policy, 45, 129-162. 
Lucas, R., (1988). On the Mechanics of Economic Development. Journal of Monetary Economics, 22(1), 3-42.

Mozgovaya, E. S. (2009). Forming the potential for sustainable development of the fuel and energy complex. Bulletin of Saratov State Social and Economic University, 4 (28), 68-75.

Natural Gas and Technology. Retrieved on 01 April 2019 from, http://naturalgas.org/

Neelova, E. Y., Kobylinskiy, D. A., Savchenkov, A. L., Golozubenko, E. S. (2018). Internal and external inspection of 3D geological model construction quality. Periodico Tche Quimica, 15(Special Issue 1), 206-213.

Onyusheva, I., Ushakov, D., \& Van, H. T. (2018). The eco-problems and green economy development in Kazakhstan: An analytical survey. International Journal of Energy Economics and Policy, 8(2), 148-153.

Patriota, S. N., Cerutti, M. N., Mulholland, D. S., Marques, M. A., Scheidt, G. N. (2016). Potential waste of agro-industrial in developing adsorbents of heavy metals. Periodico Tche Quimica, 13(25), 42-51.

Pivovarov, S. E., Tarasevich, L. S., \& Majzel, A. I. (2011). International management. Saint Petersburg: Piter.

Portella, C. M. D. A., Cavalcanti, E. H. S., Resende, V. L. D., Silva, F. D. S., Simões, M. G. P. D. A. (2017). Realignment of quality management system for improving the reliability of a biofuel laboratory. Periodico Tche Quimica, 14(27), 75-82.

Rocha, J. A., Royo, V. D. A., Menezes, E. V. (2016). Biodiesel production and paper chromatography in organic chemistry teaching. Periodico Tche Quimica, 13(26), 5258.

Sakulyeva, T., \& Kseniia, Z. (2019). The single window mechanism in the field of external sector of the economy. International Journal of Civil Engineering and Technology, 10(2), 2205-2212.

Samarina, V., Skufina, T., Samarin, A., \& Ushakov, D. (2018). Alternative energy sources: Opportunities, experience and prospects of the Russian regions in the context of global trends. International Journal of Energy Economics and Policy, 8(2), 140-147.

Silagadze, A. (2018). Some aspects of economic ideas in Shota Rustaveli's "the knight in the panther skin". Bulletin of the Georgian National Academy of Sciences, 12(1), 161167.

Syrtsov, D., \& Syrtsova, O. (2017). The International High-technological Projects Regulators: Problems and Solutions. In: International Relations 2017: Current issues of world economy and politics. $18^{\text {th }}$ International Scientific Conference, (pp.285294). Bratislava: Publishing Ekonóm.

Ushakov, D., \& Kharchenko, L. (2018). Environmental factors of national competitiveness in modern MNCs' development. International Journal of Ecological Economics and Statistics, 38(2), 141-149.

Ushakov, D., Akhmetova, S. G., \& Nevskaya, L. V. (2017a). Economic growth and environmental performance: Correlation issues and future priorities. International Journal of Ecological Economics and Statistics, 38(4), 164-172.

Ushakov, D., Elokhova, I., \& Kozonogova, E. (2017b). Post industrialization prospects in the dynamics of socioeconomic transformations: Cluster approach. International Journal of Ecological Economics and Statistics, 38(2), 23-32.

Veselovskiy, M. Y., \& Kirova, I. V. (2016). Innovative Processes in the Russian Economy. Moscow: Nauchnyj konsultant.

Workshop materials "The Shale Gas Revolution: Risks and Opportunities for Russia". (2010, 2 December). Retrieved on 18 March 2019 from, http://www.imemo. ru/ru/conf/2010/021210/021210 2.pdf

Zang, V.-B. (1999). Synergetic economy. Moscow: Mir 